\title{
University ranking: a dialogue on turning towards alternatives
}

\author{
Sarah Amsler* \\ Centre for Educational Research and Development, Bridge House, University of Lincoln, Lincoln LN6 7TS, UK
}

\begin{abstract}
This article, written as a critical dialogue between 2 interlocutors, puts forward a number of arguments justifying and criticizing the practice of university ranking. It draws attention to 3 key problematics: the ideological construction of institutional ranking as a professionally necessary and inevitable activity, the symbolically violent character of ranking as a form of social categorization and hierarchization, and the possibility of denying the system legitimacy by practicing more prefigurative forms of its critique. Through the progression of this dialogue, the article ultimately makes a case for turning away from university rankings on both scientific and ethicopolitical grounds.
\end{abstract}

KEY WORDS: University ranking · Academic capitalism · Governmentality · Prefigurative politics · Symbolic violence $\cdot$ Denaturalization

Resale or republication not permitted without written consent of the publisher

\section{INTRODUCTION}

There is a tendency to think that what we see in the present moment will continue. We forget how often we have been astonished by the sudden crumbling of institutions, by extraordinary changes in people's thoughts, by unexpected eruptions of rebellion against tyrannies, by the quick collapse of systems of power that seemed invincible.

(Zinn 2007, p. 70)

I have decided not to write another article about the global ranking of universities.

\section{Really? Why?}

We are drowning in words about rankings: how they emerged, how to design them, how to theorize them, their classifications and comparisons, the extent of their effectiveness for different purposes, why to critique them, why to defend them, improvements that will make them methodologically robust, etc. Writing about rankings has become a global business. What more can possibly be said? It has begun to feel like screaming into the wind.
But you wrote about this phenomenon not long ago (Amsler \& Bolsmann 2012). You argued that the practice of ranking is an act of symbolic violence and a mechanism of social exclusion; that it is ethically unjustifiable and politically problematic. Surely you don't still believe this, given that world university rankings have become so vital for the advancement of knowledge and higher education?

Nothing compels me to believe otherwise. In fact, many of the people who accept the practice of ranking as necessary also believe that the systems which presently prevail are mechanisms of hierarchization, stratification and exclusion, and that they obscure the political economies of knowledge production. Their arguments for rankings are not that they are ethically or politically progressive or that they are methodologically precise; only that they are structurally necessary and desirable for consolidating the power of national and transnational elites in the context of the capitalist knowledge economy. As Marginson (2009, p. 13) argues: 
These rankings are by most reasonable definitions 'unfair'. This is not a pathology of the technology. It is a mark of its uses and its rationale for existence. Rankings reflect prestige and power; and rankings confirm, entrench and reproduce prestige and power.

The monumental work of constructing a single field of vertically stratified relationships between selected universities around the world - which has also been fast work, if we consider that the first major rankings were published in 2003 and 2004-has advanced many things: various forms of competition within and between institutions, the formation of social and political policy, a greater concentration of economic and cultural capital into elite universities, the narrowing of opportunities for cross-national collaboration in research and teaching outside these elite universities, and the reshaping of academic governance and relationships within them (Hazelkorn 2007, 2013, Marginson 2009). The creation of a machinery of global hierarchization has not, on the other hand, helped to narrow educational inequalities or celebrate creative variety in intellectual work, strengthened relationships between research and teaching in any particular context, illuminated the field of non-exchange relationships between academic and social life, clarified the new politics of knowledge, or advanced complex understandings of higher education itself. Because these parameters are rationalized as inevitable and for this reason legitimate, ranking technologies are rarely regarded as violent social forms; yet, evidence suggests that they operate as such.

\section{RANKING AS SYMBOLIC VIOLENCE}

What evidence do you have that global university rankings are acts of 'symbolic violence'? I cannot understand what this means.

Symbolic violence can be understood in different ways, which we can use as tools for thinking critically about what the practice of ranking accomplishes and how it does so. Emirbayer \& Schneiderhan (2013, p. 145) define symbolic violence as 'the perpetuation of domination by means of the active complicity of the dominated', particularly 'through "bodily emotions - shame, humiliation, timidity, guilt" (Bourdieu 2001, p. 38), idealization of the oppressor, self-denigration and acceptance of the principles of evaluation favored by the dominant'.

One way to theorize the concept is thus through the work of Pierre Bourdieu, whose research on cultural power illustrated how hierarchical relations such as masculine domination are constituted and maintained as 'natural' even in the absence of discernible forces of domination. This is possible, he argued, because those occupying privileged positions are able to construct what become common categories for defining a power relationship as natural and good. Violence is enacted 'through the adherence that the dominated cannot fail to grant the dominant (and therefore to domination) when, to shape her thought of him, and herself, or rather, her thought of her relations with him, she has only cognitive instruments that she shares with him and that ... cause that relationship to appear as natural' (Bourdieu 2001, p. 35). It is violent because it unjustly limits, denies and revokes human possibility, legitimises even more economic and political forms of injustice, and arbitrarily presents an accomplished and contingent version of reality as inevitable-it 'eternalizes the arbitrary' (Bourdieu 2001, p. vii). Given the improbability that human beings would desire to be determined by others' physical power or conceptual categories, Bourdieu claimed to be 'astonished' by the fact that 'the order of the world as we find it, with its one-way streets and its no-entry signs, whether literal or figurative, its obligations and its penalties, is broadly respected; that there are not more transgressions and subversions' and that 'the established order, with its relations of domination, its rights and prerogatives, privileges and injustices, ultimately perpetuates itself so easily' (Bourdieu 1998).

Bourdieu argued that male domination was the 'prime example' of this 'paradox of doxa'. However, he also examined how this paradox plays out through the 'dehistoricization and eternalization' of inequality and injustice in both primary and higher education-specifically in France, but with resonances elsewhere. The fact that principles of hierarchization have been rooted in the very idea of the university, and thus offered a logical 'hook' for new technologies of quantitative measurement, offers insight into how the practice of ranking rapidly emerged; developed in ways that were localised, voluntary and functionally diverse; and transformed into a hyper-networked global enterprise that is militantly defended as natural, necessary, inevitable and desirable. What is particularly interesting about the practice, howeverand the point at which Bourdieu's notion of symbolic violence is no longer adequate - is that ranking is often defined in this way despite explicit sociological arguments that it is inadequate and illegitimate on methodological, epistemological and intellectual grounds. It was precisely this point that recently led 
the German Sociological Association (Deutsche Gesellschaft für Soziologie 2012) to boycott the practice, arguing:

Firstly, because the CHE Ranking has serious methodological and empirical deficiencies, secondly, because it withholds vital information from prospective students, as its declared target audience, and, thirdly, because it gives rise to wrong decisions on the part of sciencepolicy decision-makers, sociology must take a stand against this presentation of its teaching and research performance in the public sphere constructed by the media.

For an illustration of the discursive work that is being done to accomplish an aura of justified inevitability despite evidence that other interpretations are possible, consider the hypnotic mantra that is being repeated over and over again: 'rankings are here to stay' (Sanoff 1998); 'ranking systems are clearly here to stay' (Merisotis 2002); 'tables: they may be flawed but they're here to stay' (Leach 2005); 'they are here to stay' (Hazelkorn 2007); 'rankings are here to stay' (Wildavsky 2009); 'like them or not, rankings are here to stay' (Olds 2010); 'whether or not colleges and universities agree with the various ranking systems and league table findings is insignificant; ranking systems are here to stay' (UNESCOCEPES 2010); 'rankings are here to stay' (Wise 2010); 'international rankings of higher education institutions are here to stay' (UNESCO 2011); 'while many institutions had reservations about the methodologies used by the rankings compilers, there was a growing recognition that rankings and classifications were here to stay' (Osborn 2013); 'educationalists are well able to find fault with rankings on numerous grounds and may reject them outright. However, given that they are here to stay...' (Tofallis 2012).

\section{RANKING AS THE REPRODUCTION OF PRIVILEGE}

It is curious that we are so encouraged to resist asking why global university rankings are 'here to stay'. There is enough evidence that suggests that they may simply be institutionalized crystallisations of a tacit system of inequality in science, which the sociologist Robert Merton once described as the 'Matthew Effect' (Hazelkorn 2011). Merton described this as a 'psychosocial' process of stratification organized around

a principle of cumulative advantage that operates in many systems of social stratification to produce the same result: the rich get richer at a rate that makes the poor become relatively poorer. Thus, centers of demonstrated scientific excellence are allocated far larger resources for investigation than centers which have yet to make their mark' (Merton 1968, p. 7).

More recent studies suggest that such processes are at work in contemporary rankings based on peer review; for example, that pre-existing perceptions of quality and reputation have 'anchoring effects' on subsequent rankings, thus suggesting that rankings help drive the production of reputation and status rather than reflecting it (Bowman \& Bastedo 2011). Other studies illustrate the complex ways that information from rankings intersects with other decisionmaking considerations and with geographical location, class, gender and race in students' lives (Mangan et al. 2010, Broecke 2012); how it is implicated in the entrenchment of new forms of managerial governance and institutional repression in universities (Shore 2008, Marginson 2009, Sauder \& Nelson Espeland 2009, Perryman et al. 2011); and how it may be conducive to 'perverse behaviour' amongst students, academics and institutions (HEFCE 2008).

Thompson (2011) has also highlighted another concern, troublesome because it is so glaringly obvious and yet everywhere rendered invisible by ranking discourses: that the 'real' problem with university admissions is not who is recruited to the top $1 \%$ of universities, but the fact that in the US alone, $55 \%$ of college-age people do not receive a higher education at all. How many people, knowledges and possibilities are rendered invisible by this institutionalized distortion of emphasis? And yet many people - particularly those responsible for 'managing' universities and more obviously those involved in the ranking businesses themselves - seem driven to convince themselves and others that it is necessary to fix these hierarchies. In this sense, the practice of ranking does not conform to Bourdieu's theory of the 'paradox of doxa', as it is not itself a field of belief that is actually taken for granted as being beyond question. We must therefore ask what deeper doxa is underpinning the bizarre academic defence of such a troublesome intellectual practice, and what other arbitrary arrangements of power the naturalization of rankings is helping to eternalize.

I don't understand. People defend the use of global university rankings because they are helpful and because there is no alternative. Without this sort of system, students and collaborators would not be able to make informed judgements about the quality of the academic work that is done in any particular 
institution, and national governments and private sponsors will be unable to make decisions about whose work to invest in. Don't we have a moral and professional obligation to find some way of distinguishing between universities on these grounds?

If you frame the question in these terms, no answer other than 'yes' would be possible. However, this is because you have constructed the question in a way which presupposes acceptance of a constellation of other assumptions. One is that the current approaches to funding universities are adequate and effective. A second is that statistical information about discrete or multiple dimensions of an institution's work can and should be able to inform complex decisions about the potential quality of future experience, and that other criteria of judgement would not be as desirable. A third is that the knowledge and educational forms which are associated with and serve the hyper-elite are the only ones that matter. A fourth is that all institutions that desire to emulate this hyper-elite have the material resources to do so or that such resources are unnecessary. A fifth is that dominant definitions of quality and value are not in some ways simply proxies for privilege. And finally, this assumes that the idea of the university itself can be encapsulated within the political-economic horizons of the capitalist 'knowledge economy'.

Interestingly, these assumptions correspond reasonably closely to what Dorling (2011) has argued are 5 general beliefs held more widely throughout society, which make it possible for people to legitimize and sustain some very severe forms of social and economic injustice: first, that elitism is efficient; second, that exclusion is necessary; third, that prejudice is natural; fourth, that greed is good; and fifth, that despair is inevitable. He argues that questioning any of these premises will destabilize many of the systems that we presently take for granted. This includes ranking practices, which like all modern systems of hierarchical classification also rely on the stability of these beliefs. Were we to call them into question, it would become difficult to regard ranking as a just practice.

However, as universities across the world have been reorganized into more corporate institutions throughout the last 3 decades, many people have been compelled to accept these premises. The creeping tolerance of rankings as an inevitable feature of educational and scientific culture is just one example of a more widespread process in which individuals and 'governments of different political complexions take [neoliberal capitalism] as a mere fact of life (a "fact" produced by intergovernmental agreements) that all must bow to the logic of the global economy' (Fairclough 2000, p. 147). The practice of ranking both draws strength from this belief and, as a technology of classification, hierarchization and valuation, simultaneously hastens the transformation of universities into capitalist institutions that must compete against one another in an uneven market in order to survive. There is so much, and so many, being lost in this phenomenon.

\section{RANKING AS NORMALIZATION}

To better understand why people feel trapped into collaborating with the practice of ranking institutions, people and knowledges, we can turn to another tool for understanding the nature of symbolic violence. This is Michel Foucault's theory of the ways institutional systems, relations of power and discourses transform free human beings into disciplined subjects, particularly through objectification, 'dividing practices' and subjectification (Foucault 1982). Together, these practices make it possible for some actors to 'structure the possible field of the action of others' in varying degrees (Foucault 1982, p. 790). For Foucault, such games of power are endemic to and constitutive of social life itself. There are some extraordinary circumstances, he argued, in which the interplay of power and resistance becomes so channelled through institutionalised techniques of government and embodied in the subjectivities and desires of human beings themselves that 'alternative modes of action or spaces of liberty are extremely restricted' due to the durable establishment of a 'particular type of power relationship that is stable and hierarchical, fixed and difficult to reverse' (Lemke 2000, p. 5). Foucault called this special kind of situation 'domination'.

Many people will agree with me that it is excessive to define the practice of ranking universities as a situation of domination. Good people are working hard to ensure that the methodologies yield accurate, fair and transparent indicators of the quality of education around the world. If some people presently working in universities want so badly to dissociate themselves, they can easily choose to do so.

I agree that there remains a significant element of choice in this matter, although not an individualized one. However, before you assume that people are deliberately choosing to stay and comply, you may want to consider research which has been done on 
how even strong, collective opposition to the practice of ranking has been overpowered by the economic and political pressures of the social systems within which universities and people are situated.

Consider, for example, an intensive case study of the transformation of legal studies in the US and the defeat of certain law schools' initially 'vigorous' resistance to the national rankings in US News and World Report (Sauder \& Nelson Espeland 2009). Combining data from interviews, institutional documents, observations, media and other studies, Saunder and Nelson Espeland illustrate how rankings operate as technologies of power. As mechanisms of continuous, detailed surveillance, they 'dramatically magnify the visibility of law school reputations, making it difficult for schools to buffer their effects'. In the end, people's 'efforts to define their own organizations, to represent their schools in terms that capture their distinctiveness, are overwhelmed by the blunt fact of their ranking' (Sauder \& Nelson Espeland 2009, p. 76). As mechanisms of normalization, university rankings also institutionalize processes of power that, in Foucauldian terms, shape social behaviour through subtle practices of discipline, reward and punishment: comparison, differentiation, hierarchization, homogenization and exclusion (Sauder \& Nelson Espeland 2009, p. 72). As one interviewee remarked, rankings were thus 'enormously destructive to the project of law schools trying to figure out how to provide creative and innovative legal education' (Sauder \& Nelson Espeland 2009, p. 73). Threatened with marginalization, leaders of law schools nevertheless felt compelled to compete and conform.

This heightened activity of surveillance and normalization in academic work has also had affective effects. Social researchers have documented intense states of anxiety about status and security, such as Gill's (2013) demonstration of why so many academics in the UK, and particularly women, are 'exhausted, stressed, overloaded, suffering from insomnia, feeling anxious, experiencing feelings of shame, aggression, hurt, guilt and "out-of-placeness"', and Burrows' (2012, p. 13) explanation of why 'to work in the academy today inevitably involves enacting intellectual life through such metrics with all of the affective consequences that follow from this'. Another effect is the on-going micro-resistances to both the practice of ranking and the 'particular type of subjectivity that [this] discipline imposes', in a context where such resistance is often effectively 'buffered' (Sauder \& Nelson Espeland 2009, p. 75). A third is a cynical attraction to practices of ranking themselves, an 'allure' of playing the game, manipu- lating numbers and people in order to construct virtual realities in ways that can be legitimized as smart forms of adaptation. Ranking here operates as a kind of repressive public pedagogy that blurs the 'thin moral line between sensible adaptation and compromising one's values' (Sauder \& Nelson Espeland 2009, p. 77). In a recent warning to US-American academics, Barkawi (2013; all quotes below in this paragraph are from a single-page online article at http://m.aljazeera.com/story/20134238284530760) recounts how UK-based scholars began by regarding the national research audit introduced 'as if it were just some form they had to fill out, an annoying bureaucratic exercise that would not really affect us.' As a result, they - we - helped to construct a 'travesty' by pretending that 'you can rank scholarly research like you can rank restaurants or hotels so as to determine which departments have the "best" faculty'. Now, Barkawi observes, the exercise dominates all domains of academic life in most UK universities: 'academics regularly talk about each other's work in terms of whether this or that book or article is "three star" or "four star"'. More importantly, he suggests that, they take this for granted, having forgotten the purpose of scholarly work to contribute to the advancement of critical knowledge, dialogue and debate. Whether or not you choose to define such a situation as a state of domination - a claim which I accept is debatable - it is difficult to argue that it is anything but cramped.

In all, studies such as these not only illustrate that the contemporary practice of ranking universities is not a politically or ethically neutral affair, but also demonstrate how a contested set of beliefs and practices about education has been both imposed and willingly enacted as a discourse of inevitability. It is what the critical theorist Herbert Marcuse once called a historical project: 'one project among others' that 'anticipates specific modes of transforming and utilizing men and nature and rejects other modes' (Marcuse 1964, p. xvi). As Fairclough shows through his work, the production of discourses of inevitability is an essential element in the ascendance of the historical project of generalizing neoliberal capitalism. We must challenge this, he argues, because 'imposing the new world order centrally involves the reflexive process of imposing new representations of the world, new discourses' and because 'new ways of using language - new genres - are an important part of the new world' (Fairclough 2000, p. 147). From this perspective, it is easier to see that rankings are durable, but need not be 'here to stay'. They have not always been imaginable, they exist in a state of 
fragile validity only through the continual production of legitimising discourses and disciplinary institutional practices, and they could be otherwise.

\section{RANKING AS CONTESTED TERRAIN}

I agree that you are overstating the argument about the normalizing power of ranking. But it does not necessarily follow that people will desire an alternative even if the practice itself is so contingent. If so many academics, students and institutional leaders opposed the practice, we would already have seen more organized movements of resistance to the system, and someone would have come up with a preferable alternative.

This is a good point, and will allow me to clarify another misunderstanding in the debate. To argue that the practice of ranking is not inevitably 'here to stay' must not be confused with a denial that global university rankings are now institutionally locked in as mechanisms of discipline and control. It is important to be wide awake in understanding their power. As Marginson (2009, p. 5) suggests, 'in normalizing higher education as a market of competing institutions, in which "quality" is grounded in "performance" and equated with market power, and translating that market onto the global plane, the most potent mechanism is global university rankings'. Rankings may look epiphenomenal to some, but they are embedded in deep relations of political-economic power and 'made possible by a particular conjunction of discursive conditions' including (but not limited to) the 'development of a global performative hierarchy' built on top of traditional relations of inequality and exclusion in higher education; 'credentialing and knowledge cultures'; 'global communications, trade in education and new public management'; the 'world-wide organization of science and research and the growing dominance of English'; and the growing use of 'cross-country comparisons in economic policy' (Marginson 2009, p. 6). As Burrows (2012, p. 5 in an online version at http://eprints.gold.ac.uk/6560/) estimates, referring to his own national context, rankings are just one form of 'over 100 different (nested) measures to which each individual academic in the UK is now (potentially) subject'. Criticising, and moreover challenging, the practice of global rankings - which Thompson (2011) refers to as 'gnats on the back of the monster'-involves challenging much more than published comparisons of universities in newspapers and magazines.
People have resisted the idea and practice of ranking since its early phases. For years, a number of associations of colleges and universities in the US and Canada have refused to take part in the system (Annapolis Group 2007, Samarasekera 2007). The president of Reed College (US), for example, explains on the institution's admissions website that the college does not participate in ranking because rankings 'are primarily measures of institutional wealth, reputation, influence, and pedigree' which 'do not attempt, nor claim to measure the extent to which knowledge is valued and cultivated' (Reed College 2013). In a similar fashion, in June 2012, the German Sociological Association declared that it could not support the rankings of the influential Center for Higher Education because, as a professional society, it could not 'support an empirical procedure that sociology must reject on professional grounds'; in June 2013 it moved to boycott the official rankings more formally and to produce an alternative method of scholarly evaluation (Deutsche Gesellschaft für Soziologie 2012, Dörre et al. 2013, Mechan Schmidt 2013)

However, it would be insincere to gloss over the overwhelming levels of consent, resignation and acceptance of rankings amongst academics, university managers, students, and wider publics. Vocalized resignations to being ranked or to ranking others are often expressions of powerlessness. When people write that 'rankings are here to stay', they tend not to be writing in hopeful, emancipatory or even enthusiastic registers. On the contrary, they are communicating a situation of entrapment and domination: 'I do not consider this practice legitimate, yet it determines me one way or the other and so I will subject myself to it in order to survive and do the best for others'. This may be interpreted as an example of the 'cultural injustice of misrecognition', including elements of both cultural domination ('being subjected to patterns of interpretation that are associated with another culture and are alien and/or hostile to one's own') and non-recognition ('being rendered invisible by means of authoritative representational, communicative and interpretive practices') (Power \& Frandji 2010, with reference to Fraser 1997).

\section{RANKING AS MOVEABLE LIMIT SITUATION}

Given this analysis, then, I don't see why you are wasting your time screaming into this hurricane of political and economic power. Your voice is clearly no 
match for the thundering decibels of the European Union, hundreds of rectors and vice-chancellors, numerous national and international organizations, thousands of academics who are dedicating their careers in good faith to this historical quest to capture 'quality', and the millions of people-'students'around the world who are increasingly dependent on, and indeed demanding of, ranking technologies to make investment decisions in futures where all other communicative judgments of value have collapsed.

Perhaps you are right. That is, in fact, where I began: why I do not intend to write anything more about ranking.

No, you misunderstand. Your own mind is trapped in the frame you have set out to describe, and it seems now you are simply striking at limits which you mistake for objects. You say that you cannot speak, but it appears that you also cannot be silent. You already write knowing that voices such as yours cannot be heard, and yet you can hear them. You work in a university; you are as much a part of this system as anyone. Instead of screaming into the wind, why don't you turn around and try walking another way instead?

\section{Another way? Which one is that?}

Which one? There are many alternatives. Some are lying dormant in the richness of the past and in the pregnant possibilities within our everyday lives, and some have not yet been attempted. Some cannot even be imagined from within the confines of our present horizons of possibility. You claim that the dominant discourse on university ranking at the moment is relatively closed and resistant to moral, ethical or intellectual rationalities. Where there are critiques, they seem to be technical critiques of method and purpose, validity and scope, positioned either within and for the system or so radically outside of it that there is little hope of institutional transformation. However, both these positions misread the institutionalization of ranking as an objective condition rather than as a 'limit situation' that might be transgressed.

What is the difference between an inevitable situation and a limit situation?

It is impossible to say in the abstract, but a conceptual difference is that the latter implies a way of interpreting situations which is mediated through collective critical consciousness. The concept of the limit situation was introduced by Karl Jaspers, but I do not have time to explain the complexity of his theory here (for an excellent discussion, see Bornemark 2006). Jaspers was concerned to understand how people's responses to the borders between possibility and impossibility in their lives shaped the type of person they became, and vice versa. Here, however, I rely more on its situated meaning as given by the Brazilian educator Paulo Freire, who adopted the idea for his own theories of educational and political consciousness. His definition of the limit-situation involves 4 major elements: first, a belief that the historical situations we are born into and live within are complex and contingent; second, that most situations afford opportunities for us to engage in 'limit acts' which enable us to transgress the obstacles to a flourishing life; third, that all limit situations are political as they 'imply the existence of the persons who are directly or indirectly served by these situations' and whom we can therefore expect to struggle to defend them; and fourth, that whenever we engage in limit acts we are undertaking radical experiments in 'untested feasibility' and enacting a politics of possibility by re-reading that which is presented as inevitable as a surmountable limitation (Freire 2004).

Are you implying, then, that we only have to reimagine the entire system of global university rankings as a 'limit situation' in order for its classificatory and disciplinary powers to dissipate, for universities to disentangle themselves from the neoliberal logics with which many have become intertwined, and for entirely new systems of cognitive and cultural value in higher education to emerge? Surely, if it were this easy it would already have been accomplished.

I am implying nothing of the sort. You yourself have already convinced me that the practice of ranking has become deeply embedded in the organizational culture of many universities, regardless of whether they are 'world class', 'striving' or statistically invisible; that it has permeated academic subjectivities; and that choosing both to 'play the game' and to forfeit it have material consequences for individuals and institutions alike. Of course, if a critical mass of academics and students withdrew their participation and consent, the functions and legitimacy of the practice would become more questionable. But this is not a movement that should be counted on, 
and conditions are not yet in place to support a coherent alternative. To say that something is not inevitable is different from saying that its power is illusory. It is important to understand how and why rankings work so effectively as technologies of disciplinary power in contemporary educational contexts. Such a critical analysis is necessary if we are to find cracks and spaces of possibility in the system, from within which we can begin to transform it and ourselves. This is, of course, what Freire called an 'untested feasibility'; there are no guarantees that our alternative efforts will either be improvements on those which presently exist, or that they will disappoint (Freire 2000).

It sounds to me like you are speaking about cultivating some sort of 'prefigurative' politics to engage the transformation of education more creatively (Fielding \& Moss 2010). However, I am also reminded of Gibson-Graham's (2006, p. 194) more everyday argument that when we 'approach the existing conditions in a spirit of experimentation and generosity, we are encouraged to view them as conditions of possibility as well as of impossibility'. I see that analyzing how ranking practices operate, influence and falter in concrete contexts can help us to denaturalize them, as Bourdieu suggested we should do with all classificatory systems of ranking and hierarchization. Though this must, of course, be a critical analysis which discloses the politics of the emergence of the phenomenon, the power relations through which it is nourished and maintained, and the existing and possible alternatives, rather than a technical analysis that seeks merely to help us make rankings work better within the horizons of political meaning within which they already make sense.

I am not ready to think about ideas such as 'prefiguration'. I am not even sure that I wish to hear about 'cracks' and theories of interstitial transformation, which I suspect you learned from Holloway (2010). You have been speaking very critically about the practice of ranking, and now I want to hear your proposals for doing it differently. What do you think about the proposals for the new 'multiranks' (Van Vught \& Ziegele 2012)?

It should be clear that I do not propose ranking differently. It is the rationality and politics of the practice, not simply the methodology, which is problematic.

But what do you suggest?

\section{NOT RANKING}

Stop ranking. I do not mean to presume that you can stop other people from ranking, but suggest that we may ourselves find ways to unlearn the reproduction of this practice. You are right that I have read Holloway's (2010) work, which offers some interesting propositions. One is that in order to transform the systems that repress us, we first have to stop making and remaking them. 'We are presented', he argues, 'with a pre-existing capitalism that dictates that we must act in certain ways, and to this we reply, "no, there is no pre-existing capitalism, there is only the capitalism that we make today, or do not make"' (Holloway 2010, p. 236). Consequences follow from this just as they follow from conforming to the pressures of the ranking industries; these will always be concrete matters for analysis and decision. As I have already illustrated, and you have confirmed, there are many examples of individuals, collectivities and universities that operate in alter-global educational spaces, which are not organized around hierarchical principles of ranking and classifications, and that use modes of evaluation which privilege horizontality, difference, the minor and the queer, and a preference for people. I suggest we do precisely what you suggested we do: stop screaming into the wind and turn around to see what else is going on. If Hazelkorn (2013) is correct that people striving to occupy the highest positions in global rankings are in fact preoccupied with trying to reproduce whatever they think is happening in the top $1 \%$ of the world's universities, this leaves $99 \%$ open for exploration. Of course this is largely an already-tired metaphor, but it is a clarifying one.

And what of those who disagree with this radical position, particularly the growing majority of academics who are themselves in positions of fragile economic precarity and students increasingly burdened with debt, or people who have neither the inclination nor support to withdraw or resist in obvious ways? What about the rest of us, who feel strongly that scholarship and political work are discrete activities that should remain separate?

This is a valid criticism. We should encourage the plurality of acts of knowledge and resistance which might take shape, many of which require little more than critical friendships and the patience and courage to inhabit universities as spaces for serious intellectual work and for democratic life. It is likely that the inclination of many academics 
will be to undertake more research. While this is important, much of the social scientific research that we need to denaturalize, historicize and lay bare the contradictions of the existing ranking systems has already been done. The problem is not that the theory and evidence are censored or unknown. The problem is that they are rendered irrelevant by the logics of efficiency, performativity and economic value. It is this deeper doxa which must be made visible, denaturalized and confronted. This work cannot be done only within the physical and virtual walls of the universities, but must be undertaken everywhere: in conversations with young people and others participating in their decision-making processes, with organizations and businesses that invest time and money in universities on the basis of rankings, in communities and with autonomous groups seeking to create nonaligned, unranked and alternative institutions of higher education. Research about the methods, purposes and politics of university rankings is unlikely to be of interest to more than a minority of people with specialized interest; however, critical insight into the psychology, sociology, history and philosophy of ranking as a contemporary practice of hierarchization, competition and exclusive classification will be interesting to many more.

\section{Really? I find it difficult to imagine who might be} interested.

Imagine harder. There is now a growing movement in the UK and across Europe to mainstream cooperative forms of organization into primary, secondary and higher education; one in which ranking will find no role in helping to 'recuperate the ideas of association, solidarity and alliance, in order to liberate spaces and times for social cooperation and co-operating' (Hall 2013a; see also Hall 2013b,c, Winn 2013). There are similar critical conversations happening beyond the university as well. Recently, a new report was released about the quality of health care in a UK hospital, which has simultaneously renewed debates about the dehumanization of care in 'target cultures' and prompted the British government to propose a simplified 'rating' system for hospitals nationwide (Kline 2013). This, in turn, is generating fresh debates about the relationship between competition, regulation and human care, and new questions about the value of benchmarking, ratings and rankings of institutions (Davies \& Mannion 2013). In primary and secondary school education in the
UK, the struggles of teachers to both teach and to emotionally survive under the developing regimes of accountability, competition and league table surveillance are also well documented, but seldom politicized or connected with conditions in either universities or health care (Perryman et al. 2011, Ball \& Olmedo 2013). Consider all the older people caring for younger people in the UK - and all the younger people who are caring for older ones who are now being relentlessly targeted, tested and ranked, and then included in or excluded from all types of education. Those for whom being educated means being classified as 'second or third class', where classifications are both gateways to life chances and judgements about one's human value. They may be open-minded or seeking out alternative views. From another angle, people who rely on commercial companies that produce rankings of consumer products in order to make informed decisions about the distribution of their own limited resources might be interested to know more about how such practices work, and do not. We can talk with people who want to live in a world that is hospitable to the human variety; a world in which 'everyone fits' (Subcommandante Marcos 2001, p. 80). The question is, what forms of representation and communication, what institutional forms, are needed in order to create a democratic field of knowledge production and learning, in universities and beyond, which might make such conversations possible?

\section{POST-RANKING}

De Sousa Santos (2010, p. 13) has suggested that it is time to begin the counter-hegemonic globalization of the university and to 'create conditions for a cooperative university in solidarity with its own global role'. Far from advocating a retreat into localised or even national spheres of institutional influence, he argues that we should continue to pursue the globalization of education but oppose its capitalist forms. He calls on us to disentangle ourselves from this disciplinary grip and to redirect energy towards the creation of new kinds of institutions which facilitate the democratization of the university, equality of access, the extension of learning into communities and everyday life, action research, participatory evaluation of value, and the pursuit of cognitive justice through the celebration of the world's heterogeneous 'ecology of knowledges' (De Sousa Santos (2010, p. 13). 
To advance this project, he argues, we might need 3 things. The first is a network of universities that are understood to be interdependent rather than competitive: 'the university' becoming eco-systemic rather than individualized. 'It is not about making excellent universities share their resources in such a way that their excellence would be put at risk', he argues, but about 'multiplying the number of excellent universities, offering each the possibility of developing its niche potential with the help of the rest' (De Sousa Santos 2010, p. 11). Secondly, democratic relationships are needed between higher education institutions and communities, which enable academics and students to expand their circles of cooperation and be accountable to people's public needs rather than only those of business, industry, finance and the state. Finally, De Sousa Santos (2010) argues that we can substitute technocratic tools of evaluation, such as quantitative bibliometrics (and by extension ranking), with 'differentiated models that value the specific competencies of different groups of processors' and that can be self-managed, self-regulated and self-disciplined through the intellectual and political logics of the university itself (De Sousa Santos 2010, p. 12).

That is a big project. It demands ways of thinking and doing that do not yet quite exist. And I do not believe that even a radical transformation of the current system of world university rankings would resolve our problems of educational inequality.

Of course it would not resolve them. I have already explained that these inequalities predate the ranking systems which have reified them as natural and good. However, challenging these at least denaturalizes this status quo and liberates us to recognize and respond to these inequalities in more appropriate ways, while simultaneously reducing the amount of symbolic violence that we inflict upon ourselves and others in academic activity. It will create breathing space in which other ways of thinking and talking about the quality of knowledge and learning become possible. And because rankings are a key site of struggle within the university today, the very act of trying to transcend them-even when it cannot be successful - offers practice in denaturalizing hegemonic knowledges and embracing self-determination. This is already something.

Acknowledgements. I am grateful for the insightful and clarifying comments offered by my 2 anonymous reviewers and by M. Delkhasteh.

\section{LITERATURE CITED}

Amsler S, Bolsmann C (2012) University ranking as social exclusion. Br J Sociol Educ 33:283-301

Annapolis Group (2007) Annapolis Group statement on rankings and ratings. College News, 18 June. Available at http://collegenews.org/news/2007/annapolis-groupstatement-on-rankings-and-ratings.html

Ball S, Olmedo A (2013) Care of the self, resistance and subjectivity under neoliberal governmentalities. Critical Stud Educ 54(1):85-96

Barkawi T (2013) The neoliberal assault on academia. AlJazeera, 25 April. Available at www.aljazeera.com/ indepth/opinion/2013/04/20134238284530760.html

Bornemark J (2006) Limit-situation, antinomies and transcendence in Karl Jaspers' philosophy. SATS Nord J Phi$\operatorname{los} 7: 51-73$

Bourdieu P (1998) On male domination. Le Monde Diplomatique, 10 October. Available at http://mondediplo.com/ 1998/10/10bourdieu

Bourdieu P (2001) Masculine domination. Stanford University Press, Stanford, CA

Bowman N, Bastedo M (2011) Anchoring effects in world university rankings: exploring biases in reputation scores. High Educ 61:431-444

Broecke S (2012) University rankings: Do they matter in the UK?. Educ Econ 8:1-25

Burrows R (2012) Living with the H-index? Sociol Rev 60: 355-372

Davies T, Mannion R (2013) Will prescriptions for cultural change improve the NHS? BMJ 346:f1305, available at www.bmj.com/content/346/bmj.f1305?ijkey=sgMLU0au zlwKHWw\&keytype $=$ ref

De Sousa Santos B (2010) The university in the twenty-first century. Eurozine, 1 July. Available at www.eurozine. com/articles/2010-07-01-santos-en.html

Deutsche Gesellschaft für Soziologie (2012) Scientific evaluation, yes - CHE ranking, no: methodological problems and political implications of the CHE university ranking. German Sociological Association, Essen. Available at www.soziologie.de/index.php?id=768

Dorling D (2011) Injustice: why social inequality persists. Policy Press, London

Dörre K, Lessenich S, Singe I (2013) Boycott! German sociologists refuse to participate in academic ranking. German Sociological Association. Available at www.soziologie. de/index.php?id=768

Emirbayer M, Schneiderhan E (2013) Bourdieu and Dewey on democracy. In: Gorski P (ed) Bourdieu and historical analysis. Duke University Press, Durham, p 131-157

Fairclough N (2000) Language and neo-liberalism. Discourse Soc 11:147-148

Fielding M, Moss P (2010) Radical education and the common school: a democratic alternative. Routledge, New York, NY

Foucault M (1982) The subject and power. Crit Inq 8: 777-795

Fraser N (1997) From redistribution to recognition? Dilemmas of justice in a 'postsocialist' age. New Left Rev 212: 68-93

Freire P (2000) Pedagogy of the oppressed. Continuum, New York, NY

Freire P (2004) Daring to dream: towards a pedagogy of the unfinished. Paradigm Publishers, New York, NY 
Gibson-Graham JK (2006) A post-capitalist politics. University of Minnesota Press, Minneapolis, MN

Gill R (2013) Secrets, silences and toxic shame in the neoliberal university. In: Ryan-Flood R, Gill R (eds) Secrecy and silence in the research process: feminist reflections. Routledge, London, p 228-244

Hall R (2013a) Some notes towards a cooperative pedagogy of struggle. Richard Hall's Space, 5 July. Available at www.richard-hall.org/2013/07/05/some-notes-towardsa-co-operative-pedagogy-of-struggle/

Hall R (2013b) On the co-operative university as a field of opportunity. Richard Hall's Space, 3 July. Available at www.richard-hall.org/2013/07/03/on-the-co-operativeuniversity-as-a-field-of-opportunity/

Hall R (2013c) Some notes on the associational and democratic organising principles of a co-operative university. Richard Hall's Space, 2 July. Available at www.richardhall.org/2013/07/02/some-notes-on-the-associational-anddemocratic-organising-principles-of-a-co-operative-university/

Hazelkorn E (2007) How do rankings impact on higher education? OECD Institutional Management in Higher Education, December 2007. Available at www.oecd.org/edu/ imhe/39802910.pdf

Hazelkorn E (ed) (2011) Globalization and the reputation race. In: Rankings and the reshaping of higher education: the battle for world class excellence. Palgrave Macmillan, New York, NY, p 4-28

Hazelkorn E (2013) How rankings are reshaping higher education. In: Climent V, Michavila F, Ripolles M (eds) Los Rankings univeritarios, mitos y realidades. Tecnos, Madrid

HEFCE (Higher Education Funding Council for England) (2008) Counting what is measured or measuring what counts? League tables and their impact on higher education institutions in England. Rep HEFCE by Centre for Higher Education Research and Information, Open University, and Hobsons Research. Available at www.hefce. ac.uk/pubs/year/2008/200814/

Holloway J (2010) Crack capitalism. Pluto Books, New York, NY

Kline R (2013) Never again? Jeremy Hunt's response to the Francis Report is inadequate. Open Democracy, 17 April. Available at www.opendemocracy.net/ournhs/ roger-kline/never-again-jeremy-hunt \%E2 \% $80 \% 99$ sresponse-to-francis-report-is-inadequate

Leach J (2005) Tables: they may be flawed but they're here to stay. The Guardian, 29 November. Available at http: //www.guardian.co.uk/education/2005/nov/29/universityguide.highereducation

Lemke T (2000) Foucault, governmentality and critique. Paper presented at Rethinking Marxism, September 21-24. University of Amherst, Amherst, MA. Available at www.thomaslemkeweb.de/publikationen/Foucault, \%20 Governmentality,\%20and\%20Critique \%20IV-2.pdf

Mangan J, Hughes A, Davies P, Slack K (2010) Fair access, achievement and geography: explaining the association between social class and students' choice of university. Stud High Educ 35:335-350

Marcuse H (1964) One-dimensional man: studies in the ideology of advanced industrial society. Basic Books, New York, NY

Marginson S (2009) University rankings, government and social order: managing the field of higher education according to the logic of the performative present-as- future. In: Simons M, Olssen M, Peters M (eds) Re-reading education policies: studying the policy agenda of the 21st Century. Sense Publishers, Rotterdam, p 584-604

Mechan Schmidt F (2013) German academics boycott CHE ranking system. Times Higher Education, 21 March. Available at www.timeshighereducation.co.uk/ news/german-academics-boycott-che-ranking-system/ 2002595.article

Merisotis J (2002) On the ranking of higher education institutions. High Educ Eur 27:361-363

Merton R (1968) The Matthew effect in science. Science 159: $56-63$

Olds K (2010) World university rankings. Times Higher Education. Available at www.insidehighered.com/blogs/ globalhighered/thomson_reuters_the_2010_the_world_u niversity_rankings

Osborn A (2013) Are university rankings too powerful? University World News 267. Available at www.universityworldnews.com/article.php? story=20130412163531737

> Perryman J, Ball S, Maguire M, Braun A (2011) Life in the pressure cooker: school league tables and English and Mathematics teachers' responses to accountability in a results-driven era. Br J Educ Stud 59:179-195

> Power S, Frandji D (2010) Education markets, the new politics of recognition and the increasing fatalism towards inequality. Educ Policy 25:385-396

Reed College (2013) Admissions. Reed College institutional website. Available at http://web.reed.edu/apply/news_ and_articles/college_rankings.html

Samarasekera I (2007) Rising up against rankings. Inside. High Educ 2. Available at www.insidehighered.com/ views/2007/04/02/samarasekera

Sanoff A (1998) Rankings are here to stay; colleges can improve them. Chron High Educ 4. Available at http:// chronicle.com/article/Rankings-Are-Here-to-Stay-/9053

Sauder M, Nelson Espeland W (2009) The discipline of rankings: tight coupling and organizational change. Am Sociol Rev 74:63-82

Shore C (2008) Audit culture and illiberal governance: universities and the politics of accountability. Anthropol Theory 8:278-298

Subcomandante Marcos (2001) Fourth declaration of the Lacandon Jungle (excerpt), 1 January 1996. In: Ponce de León J (ed) Our word is our weapon: selected writings. Seven Stories Press, New York, NY, p 78-81

Thompson D (2011) The real problem with college admissions: it's not the rankings. Atlantic 26. Available at www.theatlantic.com/business/archive/2011/09/the-realproblem-with-college-admissions-its-not-the-rankings/ 245649/

Tofallis C (2012) A different approach to university rankings. High Educ 63:1-18

UNESCO (United Nations Educational, Scientific and Cultural Organization) (2011) University rankings are here to stay, reports University World News. UNESCO Education. Available at www.unesco.org/new/en/education/ themes/strengthening-education-systems/higher-education/single-view/news/university_rankings_are_here_ to_stay_reports_university_world_news/

UNESCO-CEPES (2010) Higher education ranking systems and methodologies: how they work, what they do. European Centre for Higher Education

Van Vught F, Ziegele F (2012) Multidimensional ranking: the design and development of U-Multirank. Springer, New York, NY 
Wildavsky B (2009) International studies: how America's mania for college rankings went global. Brookings (August/September). Available at www.brookings. edu/research/articles/2009/08/09-college-rankingswildavsky

Winn J (2013) Helplessness. Joss Winn, 1 July. Available at http://josswinn.org/2013/07/helplessness/

Editorial responsibility: Konstantinos Stergiou, Thessaloniki, Greece
Wise C (2010) Rankings are here to stay, so let's make the most of it. Vault Career Intelligence, 5 August. Available at www.vault.com/wps/portal/usa/blogs/entry-detail/ ?blog_id=1461\&entry_id=11680

Zinn H (2007) The optimism of uncertainty. In: Loeb P (ed) The impossible will take a little while: a citizen's guide to hope in a time of fear. Basic Books, New York, NY

Submitted: May 6, 2013; Accepted: July 19, 2013

Proofs received from author(s): August 31, 2013 